\title{
Retraction Note to: Functional analysis of newly identified RYR1 variants in patients susceptible to malignant hyperthermia
}

\author{
Yuko Noda ${ }^{1}$ (1) $\cdot$ Toshimichi Yasuda $^{1} \cdot$ Rieko Kanzaki $^{1} \cdot$ Hirotsugu Miyoshi $^{2} \cdot K^{2}$ Keiko Mukaida ${ }^{3} \cdot$ Satoshi Kamiya $^{1} \cdot$ \\ Atsushi Morio $^{1} \cdot$ Hiroshi Hamada $^{1} \cdot$ Masashi Kawamoto $^{4} \cdot$ Yasuo M. Tsutsumi ${ }^{1}$
}

Published online: 2 November 2020

(c) Japanese Society of Anesthesiologists 2020

\section{Retraction Note to: Journal of Anesthesia (2020) 34:658-665 https://doi.org/10.1007/s00540-020-02803-w}

The authors have retracted this article [1] because they did not have permission to use the data in Tables 1 and 2. All authors agree to this retraction.

\section{Reference}

1. Noda Y, Yasuda T, Kanzaki R, et al. Functional analysis of newly identified RYR1 variants in patients susceptible to malignant hyperthermia. J Anesth. 2020;34:658-65. https://doi.org/10.1007/ s00540-020-02803-w.
Publisher's Note Springer Nature remains neutral with regard to jurisdictional claims in published maps and institutional affiliations.

The original article can be found online at https://doi.org/10.1007/ s00540-020-02803-w.

Yuko Noda

nodananoda0724@yahoo.co.jp

1 Department of Anesthesiology and Critical Care, Graduate School of Biomedical Sciences, Hiroshima University, 1-2-3 Kasumi, Minami-ku, Hiroshima 734-8551, Japan

2 Department of Anesthesiology and Critical Care, Hiroshima University Hospital, Hiroshima, Japan

3 Department of Anesthesiology, Hiroshima Prefectural Rehabilitation Center, Higashi-hiroshima, Japan

4 Medical Corporation JR Hiroshima Hospital, Hiroshima, Japan 